\title{
$\begin{array}{ll}\text { Research Square } & \begin{array}{l}\text { Preprints are preliminary reports that have not undergone peer review. } \\ \text { They should not be considered conclusive, used to inform clinical practice, } \\ \text { or referenced by the media as validated information. }\end{array}\end{array}$
}

\section{Response Surface Methodology for Optimization of Rotating Biological Contactor Combined With An External Membrane Filtration}

\author{
Sharjeel Waqas \\ Universiti Teknologi Petronas: Universiti Teknologi PETRONAS \\ Noorfidza Yub Harun \\ Technology University of Petronas: Universiti Teknologi PETRONAS \\ Muhammad Roil Bilad ( $\sim$ roil.bilad@ubd.edu.bn ) \\ Universiti Brunei Darussalam https://orcid.org/0000-0001-7292-6046 \\ Taufik Samsuri \\ Universitas Pendidikan Indonesia \\ Nik Abdul Hadi Nordin \\ Technology University of Petronas: Universiti Teknologi PETRONAS
}

\section{Research Article}

Keywords: Analysis of variances (ANOVA), attached growth process, biofilm, biological wastewater treatment, response surface methodology (RSM), Box-Behnken design (BBD), membrane fouling, rotating biological contactor

Posted Date: August 24th, 2021

DOI: https://doi.org/10.21203/rs.3.rs-819469/v1

License: (c) (i) This work is licensed under a Creative Commons Attribution 4.0 International License. Read Full License 


\section{Abstract}

A large amount of wastewater is directly discharged into water bodies without treatment causing surface water contamination. Conventional treatment techniques produce lower effluent quality and are energy extensive. Rotating biological contactor (RBC) is an attractive biological wastewater treatment that offers a low energy footprint. However, its unstable removal efficiency makes it less popular. This study optimizes operating parameters in RBC combined with external membrane filtration (RBC-ME) in which the latter acts as a post-treatment step to stabilize the biological performance. Response Surface Methodology (RSM) was employed to optimize the biological and filtration performance by exploiting three parameters of disk rotational speed, hydraulic retention time (HRT), and sludge retention time (SRT). Results show that RBC-ME exhibits excellent biological treatment capacity and higher effluent quality. It attained $87.9 \pm$ $3.2 \%$ of chemical oxygen demand, $45.2 \pm 0.7 \%$ total nitrogen, $97.9 \pm 0.1 \%$ turbidity, and $98.9 \pm 1.1 \%$ ammonium removals. The RSM data demonstrated that the experimental data and model predictions agreed well. Under the most optimum parameters, the permeability of $144.6 \mathrm{~L} / \mathrm{m}^{2} \mathrm{~h}$ bar could be achieved at $36.1 \mathrm{rpm}$ disk rotational speed, $18 \mathrm{~h} \mathrm{HRT}$, and 14.9 d SRT. This work demonstrates the effective use of statistical modeling to enhance RBC-ME system performance to obtain a sustainable and energy-efficient treatment process to prevent human health and the environment.

\section{Article Highlights}

- Membrane integrated RBC offers better biological performance than stand-alone RBC.

- Longer hydraulic and sludge retention time enhance permeability.

- Biofilm detachment limits the disk rotational speed.

- RSM helps to identify the significant operating factors and optimum levels with minimum effort and time.

\section{Introduction}

Biological methods have been widely adapted in wastewater treatment with the advantages of more cost-efficient, smaller footprint requirements, higher specific biomass activities, and sustainable and environmentally friendly (Liu et al., 2021; Fito et al., 2019). Stringent effluent standards imposed by regulatory authorities highlighting the need for the development of a sustainable and environmentally friendly treatment process (Ashraf et al., 2021; Preisner, 2020). Rotating biological contactors (RBC) rely on the rotating party submerged disks to grow biofilm that is kept in constant motion for energyefficient aeration. The longer sludge retentions time (SRT) able the growth of the nitrifying community throughout the biofilm, to perform complete nitrification (Šíma et al., 2016). In RBC, sufficient microbial growth on the rotating disks exploits the benefit of high effluent quality and treatment efficiency. The RBC bioreactor has been utilized to achieve steady-state nitrification round the year and to improve removal efficiency and treatment capacity due to the liberty to multiplicate the mixed liquor suspended solids (MLSS). RBC operates at a high microbial concentration that allows a higher organic loading rate (Vasiliadou et al., 2016). Like in the membrane bioreactor, RBC can further be extended by incorporating membrane filtration for sludge separation. Recently, various RBC configurations appear as a promising alternative to the traditional treatment processes and they have been applied for the treatment of both municipal and industrial wastewaters (Waqas and Bilad, 2019).

Membrane integrated RBC has been explored to enhance the physical and biological operation of the bioreactor.

Membrane integrated RBC employs membrane technology as post-treatment eliminating the need for a settling tank. The operational parameters, SRT, hydraulic retention time (HRT), and disk rotational speed have a considerable influence on microbial activity and membrane fouling potential (Su et al., 2019). These operational parameters can alter microorganism properties and helps in optimizing the system's performance. Recent studies have shown that short HRT results in a high organic loading rate which could increase the viscosity and sludge concentration as well as increase the filamentous bacteria growth (Deng et al., 2016). Recent studies have depicted that disk rotational speed, HRT, and SRT 
influence the biodegradation process and micro-pollutant removal in membrane systems (Waqas et al., 2020a; Gkotsis et al., 2017).

The relationship and optimization of the operational parameters can help to increase the performance efficiency of the bioreactor. Hence, the design of experiments (DOE) is an excellent choice to optimize the process parameters. The DOE acquires fewer experiments and statistically predictable with highly reliable and efficient results. Response surface methodology (RSM) is an excellent example of such an approach in enhancing the performance efficiency of bioreactors and can study the behavior of various parameters simultaneously (Abdulgader et al., 2020). RSM is an empirical statistical technique that can investigate mathematical modeling to comprehend the mutual relationship of various process parameters on the response variable. The quantitative data is generated from the design of experiments and analysis of regression models and operational conditions can result in high-end performance (Belgada et al., 2020).

Biological wastewater treatment incorporating membrane separation has been the focus of research worldwide (Baneshi et al., 2020; Sheth et al., 2021; Bezirgiannidis et al., 2018). Some studies have focused on the optimization of the operating conditions of the membrane process. Askari et al., (Askari et al., 2018) studied RSM for the examination of the effect of process conditions on the NF membrane removal efficiency. The operational parameters, disk rotational speed, HRT, and SRT have a significant influent on microbial community concentration, biological performance, and membrane fouling propensity (Nuansawan et al., 2016; Deng et al., 2016). Disk rotational speed, HRT, and SRT can alter the extracellular polymeric substances secretion, sludge settling characteristics, and mixed liquor properties. However, no research work has been documented to optimize process parameters in RBC integrated with external membrane bioreactor using polysulfone membrane.

In this study, RSM modeling and optimization technique was utilized to investigate the relationship between different variables via establishing the predicted models. Box-Behnken design (BBD) through RSM was employed to examine the effect of three operational parameters (disk rotational speed, HRT, and SRT) on membrane permeability. The objective of this study is to investigate the relationship between operational parameters (disk rotational speed, HRT, and SRT) and the response parameter of permeability and to find the optimal condition of the process by using RSM. During experimentation, different operational parameters (disk rotational speed, HRT, and SRT) values were altered through variable speed shaft motor, an increase of organic loading rate and sludge wastage rate, respectively and performance of RBC combined with external membrane filtration (RBC-ME) bioreactor was analyzed. The optimization of membrane incorporated wastewater treatment process improves membrane permeability and reduces the operational cost of the process.

\section{Methods And Materials}

\subsection{Wastewater preparation and bioreactor acclimatization}

The lab-scale RBC-ME bioreactor was fed with the synthetic wastewater prepared by blending food leftover as suggested in our previous study (Waqas et al., 2020c) and achieved influent wastewater concentrations are summarized in Table 1. 
Table 1

Influent characteristics for the RBC-ME bioreactor employing the polysulfone membrane in the post-treatment.

\begin{tabular}{|ll|}
\hline Component & Influent \\
\hline COD $(\mathrm{mg} / \mathrm{L})$ & $282.8 \pm 8.3$ \\
\hline $\mathrm{TN}(\mathrm{mg} / \mathrm{L})$ & $2.5 \pm 0.02$ \\
\hline Ammonia $(\mathrm{mg} / \mathrm{L})$ & $0.64 \pm 0.07$ \\
\hline Nitrate $(\mathrm{mg} / \mathrm{L})$ & $0.54 \pm 0.02$ \\
\hline Turbidity $(\mathrm{NTU})$ & $14.6 \pm 0.1$ \\
\hline pH & $6.25 \pm 0.03$ \\
\hline RBC-ME: rotating biological contactor-membrane external, COD: chemical oxygen demand, TN: total nitrogen \\
\hline
\end{tabular}

\subsection{Membrane preparation and properties}

A flat sheet polysulfone (PSF) membrane was fabricated in-house and used during the experiments. The membrane was fabricated using PSF as polymer, polyethylene glycol (PEG) as an additive, and N N-Dimethylacetamide (DMAc) as solvent through the phase inversion technique. PSF, PEG, and DMAc were used at a concentration of $12 \%, 1 \%$, and $87 \%$ respectively. Detailed procedure for the manufacturing and characterization is given in our previous study (Waqas et al., 2021d). The dope solution was kept for $24 \mathrm{~h}$ without any mixing to release the entrapped air bubbles. Entrapped air bubbles can cause defects in the membrane sheet hence air bubbles-free dope solution is necessary. The prepared dope solution was cast through the phase inversion method as described in our previous study (Waqas et al., 2021d).

\subsection{Bioreactor set-up}

The RBC-ME bioreactor consisted of a feed wastewater tank, RBC bioreactor and external membrane vessel was constructed in-house as shown in Fig. 1. The feed wastewater tank of capacity $42 \mathrm{~L}$ was used as a storage vessel to supply a constant supply of wastewater to the RBC bioreactor. The feed tank was facilitated with a mechanical stirrer to maintain the uniform concentration of wastewater throughout the storage vessel. The RBC bioreactor consisted of a $25 \times 25 \times 30 \mathrm{~cm}$ tank fabricated from poly (methyl methacrylate) and had a working volume of $6.5 \mathrm{~L}$. The bioreactor was equipped with 5 rotating disks of $1.8 \mathrm{~cm}$ thickness and $18 \mathrm{~cm}$ diameter mounted on a stainless-steel shaft. The shaft was attached to a DC motor that rotates the disks. The disks were also fabricated from poly (methyl methacrylate) equivalent to a net surface area of $2034 \mathrm{~cm}^{2}$ and placed inside the RBC bioreactor at $40 \%$ submergence. The disks were attached to polyurethane sheets $\left(1.22-1.27 \mathrm{~g} / \mathrm{cm}^{3}\right.$ density) to colonize the microbial population. The flat sheet membrane module was placed after the RBC bioreactor acting as a post-treatment. The RBC-ME system did not include a settling tank (typically a part of a conventional RBC unit), which was replaced with a membrane filtration tank. The permeate was collected from the filtration cell and its volume was measured regularly.

\subsection{Bioreactor operation}

The lab-scale RBC-ME bioreactor was inoculated from the activated sludge obtained from the nearly full-scale domestic wastewater treatment plant. The bioreactor was operated for 45 days, divided into two phases. During the first phase, the bioreactor was operated on for 17 days to fully acclimatize the biofilm. The feed wastewater organic loading rate was kept constant at $19 \mathrm{~g}$ chemical oxygen demand (COD) $/ \mathrm{m}^{2} \mathrm{~d}$ and biofilm formed at the rotating disks was observed for any changes. The membrane panel was placed into the system after biofilm acclimatization and to study the impact of membrane permeability performance under various parameters. 
The experimental investigation was done for three operating parameters (disk rotational speed, HRT, and SRT). The disk rotational speed was set from 30 to $50 \mathrm{rpm}$, HRT was set from 9 to $15 \mathrm{~h}$ and SRT was set from 5 to 15 days. The disk rotational speed was increase with the variable speed DC motor; flow rate was increased to increase the HRT while SRT was varied by wasting a portion of the reactor volume each day.

\subsection{Analytical methods}

COD, total nitrogen (TN), ammonia, and nitrate were measured using the specific Hach digestion solution (HACH, Loveland, USA) for each compound. The solution was diluted to fall into the range of the digestion vials being used for the study. The values were determined through Hach DR3900 Spectrophotometer (HACH, Loveland, USA). Hach 2100Q portable turbidimeter (HACH, Loveland, USA) and Hach HQ411D benchtop PH/MV meter (HACH, Loveland, USA) were used to determine turbidity and $\mathrm{pH}$, respectively (APHA, 1997).

\subsection{Determination of filtration performance}

The low pressure for filtration not only reduces the energy cost, but it also is less susceptible to membrane fouling and maintains sustainable flux as reported elsewhere (Bilad et al., 2020). The membrane permeability $(L), L / \mathrm{m}^{2} \mathrm{~h}$ bar) was calculated by using Eq. 1 .

$$
L=\frac{\Delta V}{A \Delta t \Delta \mathrm{P}}
$$

where $\mathrm{V}$ is the volume of permeance $(\mathrm{L}), \Delta \mathrm{P}$ transmembrane pressure (bar), $\mathrm{t}$ filtration time $(\mathrm{h})$, and $\mathrm{A}$ membrane area $\left(\mathrm{m}^{2}\right)$.

\subsection{Experimental design by RSM method}

RSM is an aggregation of mathematical and statistical approaches accommodating to examine the effectiveness of various operational parameters. Design Expert software (DES) version 8.0.6 was applied to evaluate the response of various parameters (Zulfiqar et al., 2019; Malika and Sonawane, 2021). DES not only analyzes the parameters; it also helps to determine the projected outcomes to compare with the actual values. It can also help to predict the optimized values for the independent operational parameters (Zulfiqar et al., 2020a; Zulfiqar et al., 2020b). To scrutinize the impact of various operational parameters on the membrane fouling propensity in RBC-ME configuration, a 3-variables with 3-level BBD model was employed holding 3 central points per block. A 3-level BBD depicts that each numeric factor is varied over

3 levels. Three independent operational parameters are (i) disk rotational speed, (ii) HRT, and (iii) SRT. The BBD consists of three levels: high level or maximum (referred to as + 1), medium level or central (referred as 0), and low level or minimum (referred as -1) for all operating parameters. The disk rotational speed varied from 30-50 rpm; HRT was in the range of 12-18 h while SRT was varied from 5-15 days. The independent variables and their range utilized are enrolled in Table 2. The 3 independent variables are presented as A, B and C respectively for statistical computations. The resulting response of membrane permeability was determined to investigate the influence of variables. The results of response date were analyzed with analysis of variance (ANOVA) if liable term composed a powerful effect $(p \leq 0.05)$. Evaluate model fit and transformation to graphs to interpret and evaluate the model prediction results. 
Table 2

Independent variables and levels using in Box-Behnken design.

\begin{tabular}{|lllll|}
\hline Levels & Independent variable & Low level (-1) & Medium level $(\mathbf{0})$ & High level (+ 1) \\
\hline 1 & Disk rotational speed & 30 & 40 & 50 \\
\hline 2 & HRT & 12 & 15 & 18 \\
\hline 3 & SRT & 5 & 10 & 15 \\
\hline
\end{tabular}

\section{Results And Discussion}

\subsection{Biological performance}

Table 1 summarizes the biological performance of the RBC-ME bioreactor employing the PSF membrane for synthetic wastewater treatment. The operation of RBC stabilized after approximately $30 \mathrm{~d}$ of operation ascribed from the profile of pollutant removals. The results enlisted in Table 1 were determined after the acclimatization time, showing a stable biological performance as depicted from steady removal efficiencies. The synthetic domestic wastewater used as the RBC feed contained a high number of organics. Therefore, carbonaceous bacteria undertaken the removal of the organics were expected to dominate in the biofilm. The high abundance of carbonaceous bacteria biodegraded the readily available substrate (organic pollutants). The RBC-ME bioreactor demonstrated excellent biological removal efficiencies in terms of COD, ammonium, TN, phosphorus, and turbidity (Table 1).

Table 1 summarizes the biological performance of the RBC-ME bioreactor employing the PSF membrane for synthetic wastewater treatment. The operation of RBC stabilized after approximately $30 \mathrm{~d}$ of operation ascribed from the profile of pollutant removals. The results enlisted in Table 3 were determined after the acclimatization time, showing a stable biological performance as depicted from steady removal efficiencies. The synthetic domestic wastewater used as the RBC feed contained a high number of organics. Therefore, carbonaceous bacteria undertaken the removal of the organics were expected to dominate in the biofilm. The high abundance of carbonaceous bacteria biodegraded the readily available substrate (organic pollutants). The RBC-ME bioreactor demonstrated excellent biological removal efficiencies in terms of COD, ammonia, TN, and turbidity (Table 3 ).

Table 3

Effluent characteristics for the RBC-ME bioreactor employing the polysulfone membrane in the post-treatment.

\begin{tabular}{|lll|}
\hline & RBC-ME effluent & $\begin{array}{l}\text { RBC-ME } \\
\% \text { removal efficiency }\end{array}$ \\
\hline COD $(\mathrm{mg} / \mathrm{L})$ & $35 \pm 7.5$ & $87.6 \pm 2.7$ \\
\hline $\mathrm{TN}(\mathrm{mg} / \mathrm{L})$ & $1.37 \pm 0.06$ & $45.2 \pm 2.6$ \\
\hline Ammonia $(\mathrm{mg} / \mathrm{L})$ & $0.01 \pm 0.01$ & $98.5 \pm 0.07$ \\
\hline Nitrate $(\mathrm{mg} / \mathrm{L})$ & $1.8 \pm 0.2$ & - \\
\hline Turbidity $(\mathrm{NTU})$ & $0.32 \pm 0.03$ & $97.8 \pm 0.2$ \\
\hline pH & $6.95 \pm 0.11$ & - \\
\hline RBC-ME: rotating biological contactor-membrane external, COD: chemical oxygen demand, TN: total nitrogen \\
\hline
\end{tabular}


The results show significantly higher removal efficiencies for the COD, TN, ammonia, and turbidity of 87.6 $\pm 2.7,45.2 \pm 2.6$, $98.5 \pm 0.07$, and $97.8 \pm 0.2$, respectively. The higher efficiency for COD and ammonia can be attributed to the high microbial activity of carbonaceous and ammonia oxidizing bacteria (Waqas et al., 2021c; b). An increase in effluent nitrate concentration $(1.8 \pm 0.2)$ is due to poor anoxic conditions within the biofilm resulting in a low concentration of nitrate oxidizing bacteria. In the attached growth system, the relative position of the biofilm to the surface affects the oxygen concentration, being the lowest (anoxic) in the deeper part. It can be speculated that the formed biofilm on the substrate media was still too thin to exert the required anoxic condition for denitrification. Higher removal efficiency for turbidity was achieved by the RBC-ME bioreactor due to the membrane separation. The results showed the turbidity value substantially diminished from $14.6 \pm 0.1$ NTU to $0.32 \pm 0.03$ NTU in the RBC-ME attributes to $97.8 \pm 0.2 \%$ removal efficiencies (Table 3 ).

Replacement of secondary settling tank with the membrane separation enabled the system to achieve removal efficiency not too dependent on the sludge settling characteristics (Waqas et al., 2020b). Any sludge produced by the detachment of the attached biofilm flocs on the substrate could readily be removed from the bioreactor. Removal of suspended biomass flocs resulted in higher nitrogen and phosphorous removal efficiencies as reported earlier (Mannina et al., 2018; Waqas et al., 2021a). The solid-liquid separation process ensures high effluent quality in terms of organics and nutrients. Consequently, the biological performance can be enhanced by increasing the biomass SRT.

\subsection{Statistical analysis and model development}

Table 4 shows three factors BBD matrix showing the independent variable and response of membrane permeability. The three operating parameters of disk rotational speed, HRT, and SRT were selected based on our earlier published data (Waqas et al., 2021c) according to their contribution to biodegradation and membrane fouling. The three-level BBD was used to perform the analysis with a total of 15 experimental runs. The permeability values over each set of parametric values were used to establish a statistical model. 
Table 4

Box-Behnken design matrix for independent variable and response of membrane permeability at three-factor levels.

\begin{tabular}{|llllll|}
\hline \multicolumn{3}{|c}{ Independent variables } & & \multicolumn{3}{c|}{ Permeability (L/m ${ }^{2}$ h bar) } \\
\hline Run & $\begin{array}{l}\text { (A) Disk rotational speed } \\
\text { (rpm) }\end{array}$ & $\begin{array}{l}\text { (B) HRT } \\
(\mathbf{h})\end{array}$ & $\begin{array}{l}\text { (C) SRT } \\
(\mathbf{d})\end{array}$ & Actual value & Predicted value \\
\hline 1 & 40 & 15 & 10 & 138 & 137.33 \\
\hline 2 & 30 & 12 & 10 & 133 & 133.63 \\
\hline 3 & 30 & 15 & 15 & 139 & 139.38 \\
\hline 4 & 50 & 12 & 10 & 120 & 120.63 \\
\hline 5 & 30 & 15 & 5 & 133 & 132.63 \\
\hline 6 & 40 & 15 & 10 & 136 & 137.33 \\
\hline 7 & 40 & 12 & 5 & 131 & 130.75 \\
\hline 8 & 50 & 18 & 10 & 115 & 114.38 \\
\hline 9 & 30 & 18 & 10 & 140 & 139.38 \\
\hline 10 & 50 & 15 & 5 & 109 & 108.63 \\
\hline 11 & 40 & 18 & 15 & 142 & 142.25 \\
\hline 12 & 40 & 15 & 10 & 138 & 137.33 \\
\hline 13 & 50 & 15 & 15 & 125 & 125.28 \\
\hline 14 & 40 & 18 & 5 & 126 & 127.00 \\
\hline 15 & 40 & 15 & 140 & 139.00 \\
\hline
\end{tabular}

\subsection{RSM model optimization}

Full fractional three-factor BBD was applied to investigate the effects of three independent parameters to model the steady-state membrane permeability. The results of the BBD model are described in common ANOVA (Table 5) in which the steady-state membrane permeability was set as the response (Zulfiqar et al., 2019). The ANOVA results show that the relationship between steady-state membrane permeability (units) and the experimental investigations fits well with a quadratic model with $p$ values $=0.0069$. The coded and actual factors for membrane permeability are shown in Eqs. (2) and (3).

Steady-state membrane permeability $\left(L / \mathrm{m}^{2} \mathrm{~h}\right.$ bar $)=137.33-9.50 \mathrm{~A}-0.1250 \mathrm{~B}+5.88 \mathrm{C}-3.00 \mathrm{AB}+2.50 \mathrm{AC}+1.75 \mathrm{BC}-$ $9.29 A^{2}-1.04 B^{2}-1.54 C^{2}(2)$

Steady-state membrane permeability $\left(\mathrm{L} / \mathrm{m}^{2} \mathrm{~h}\right.$ bar $)=-39.16667+7.48333 \times$ Disk rotational speed $+6.26389 \times \mathrm{HRT}-$ $1.34167 \times$ SRT $-0.1 \times$ Disk rotational speed $x$ HRT + $0.05 \times$ Disk rotational speed $\times$ SRT + $0.116667 \times$ HRT $\times$ SRT $0.092917 \times$ Disk rotational speed ${ }^{2}-0.115741 \times$ HRT $^{2}-0.061667 \times$ SRT $^{2}$ (3)

Eqs. 1 and 2 were used to predict the steady-state membrane permeability listed in Table 5, demonstrating a good agreement between the predicted and experimental data. The significance and authenticity of the proposed model were stated based on different model constraints for instance $p$ values, $R^{2}$, adjusted $R^{2}$, as well as $F$ values. $A p$-value $<0.0500$ 
implies a model as significant and insignificant if $p$ values are higher than 0.0500 . $R^{2}$ represents the coefficient of determination used to validates the quality of the proposed model. A close to 1 value of $R^{2}$ is more advantageous. The proposed model depicts an $\mathrm{R}^{2}$ value of 0.9951 , which indicates that $99.51 \%$ variations of steady-state permeability are explicable across the parameter ranges. The adjusted $R^{2}$ value of 0.9862 is close to $R^{2}$ values, depicting the goodness of quadratic model fitting. The larger $\mathrm{R}^{2}$ value confirms the excellent adaptation of the predicted model to the experimental data.

Table 5

ANOVA results of the coefficient of quadratic model for steady-state membrane permeability.

\begin{tabular}{|lllllll|}
\hline Source & Sum of & df & Mean & F & p-value & \\
& Squares & & Square & Value & Prob $>$ F & \\
\hline Model & 1393.08 & 9 & 154.79 & 111.89 & $<0.0001$ & Significant \\
\hline A-Disk rotational speed & 722.00 & 1 & 722.00 & 521.93 & $<0.0001$ & Significant \\
\hline B-HRT & 0.1250 & 1 & 0.1250 & 0.0904 & 0.7758 & Not significant \\
\hline C-SRT & 276.13 & 1 & 276.13 & 199.61 & $<0.0001$ & Significant \\
\hline AB & 36.00 & 1 & 36.00 & 26.02 & 0.0038 & Significant \\
\hline AC & 25.00 & 1 & 25.00 & 18.07 & 0.0081 & Significant \\
\hline BC & 12.25 & 1 & 12.25 & 8.86 & 0.0309 & Significant \\
\hline A $^{2}$ & 318.78 & 1 & 318.78 & 230.44 & $<0.0001$ & Significant \\
\hline B & 4.01 & 1 & 4.01 & 2.90 & 0.1495 & Not significant \\
\hline C $^{2}$ & 8.78 & 1 & 8.78 & 6.34 & 0.0533 & Not significant \\
\hline Residual & 6.92 & 5 & 1.38 & & & \\
\hline Lack of Fit & 4.25 & 3 & 1.42 & 1.06 & 0.5183 & Not significant \\
\hline Pure Error & 2.67 & 2 & 1.33 & & & \\
\hline Cor Total & 1400.00 & 14 & & & & \\
\hline
\end{tabular}

The quadratic model predicted an F-value of 111.89 which implicates that it is significant, with only a $0.01 \%$ probability it occurs due to noise. The model p-value less than 0.05 reveals the significant model terms. A p-value $>0.05$ implicates the model term as non-significant. Table 5 shows that model terms $A, C, A B, A C, B C$ and $A^{2}$ are significant while $B, B^{2}$, and $C^{2}$ are insignificant. A non-significant value for Lack of fit is required for a well-fit model. ANOVA shows a 1.06 lack of fit which implicates a non-significant relation to the pure error. It implies that the predicted quadratic model can be utilized to circumnavigate the design space.

A diagnostic plot such as the predicted versus actual values shown in Fig. 2 supports adjudicating the model satisfactoriness visually. Figure 2 indicates an adequate agreement between real data and the ones obtained from the models. A model normally can be considered reproducible if its coefficient of variance (CV) is less than $10 \%$. The quadratic model represents a CV value of $0.8978 \%$ indicating good reproducibility of the model. 
Table 6

Various parametric values of the Box-Behnken design.

\begin{tabular}{|c|c|c|c|c|c|c|c|c|c|c|}
\hline Source & $\begin{array}{l}\text { Sequential } \\
\text { p-value }\end{array}$ & $\begin{array}{l}\text { Lack } \\
\text { of Fit } \\
\text { p- } \\
\text { value }\end{array}$ & $\mathrm{R}^{2}$ & $\begin{array}{l}\text { Adjusted } \\
\mathrm{R}^{2}\end{array}$ & $\begin{array}{l}\text { Predicted } \\
\mathbf{R}^{2}\end{array}$ & $\begin{array}{l}\text { Model } \\
\text { F- } \\
\text { value }\end{array}$ & $\begin{array}{l}\text { Lack } \\
\text { of Fit } \\
\text { F- } \\
\text { value }\end{array}$ & $\begin{array}{l}\text { Std. } \\
\text { Dev. }\end{array}$ & AP & CV (\%) \\
\hline Quadratic & $<0.0001$ & 0.5183 & 0.9951 & 0.9862 & 0.9471 & 111.89 & 1.06 & 1.18 & 35.0142 & $0.897 \varepsilon$ \\
\hline
\end{tabular}

\subsection{Process analysis}

Membrane permeability is affected by operational parameters, that can exist in neutral, positive, or negative configurations. Those parameters can also significantly affect biological performance and effluent quality. Therefore, the study of the influence of these parameters on the steady-state membrane permeability can help to optimize the whole process (biodegradation and permeability). The dependency of the operational parameters on the membrane permeability is presented in Fig. 3 in the form of 2-D contour and 3-D response surface plots. Response surface diagrams illustrate regression equation models utilized to fathom the optimum status of multiple parameters, explains interactions between factors, and ultimately used to enhance the efficiency of the process.

Figure 3 shows the response surface plots for steady-state permeability. The plots are approximately symmetrical in shape with circular contours. Response surface plots indicate the relative importance of three operating parameters. All response plots demonstrate clear peaks, indicating the optimized parameter (disk rotational speed, HRT and SRT) values for the maximum value of the membrane permeability in the design space.

The 2-Dcontour and 3-D response surface plots in Fig. 3a and d reveal the interactions between the speed of the disk rotational and HRT pose a significant effect on the permeability. A lower disk rotational speed and higher HRT results in higher permeability. The decline in permeability can be described by the enhanced shear rate produced by higher disk rotational speed. The shear rate results in the shredding of biofilm flocs that suspend and block the membrane pores (Zhang et al., 2015; Luo et al., 2012). As the disk rotational speed increases to beyond $40 \mathrm{rpm}$, the permeability decreases. However, a less significant effect was found for the HRT because of the higher organics ratio and lower nitrogen concentration (Huang et al., 2011). All the organics are readily degraded and do not require higher HRT resulting in good performance even at low HRTs. Removal efficiencies decrease when moving away from these points, which means either a decrease or increase in any of the tested variables results in the decline of the permeability.

Figure $3 \mathrm{~b}$ and e show the 2-D contour and 3-D response surface plots between disk rotational speed and SRT, depicting that higher disk rotational speed from 30 to $40 \mathrm{rpm}$ at SRT values from 10 to 15 days leads to higher permeability; while beyond $40 \mathrm{rpm}$, the permeability gradually decreases. Shorter SRT results in poor settling of sludge increasing the membrane resistance by blocking the membrane pores (Jang et al., 2021). Higher SRT means retention of microbial community for a longer time in the bioreactor and thus lower sludge production.

The interaction between HRT and SRT as shown in Fig. 3c and f reveals that higher HRT and SRT increases, as also reported elsewhere (Berkessa et al., 2018). With the increase of both HRT and SRT from $12 \mathrm{~h}$ and $5 \mathrm{~d}$, respectively, an increase in permeability is observed. Indeed, the membrane permeability further increases at higher HRT and SRT. HRT seems just slightly affect permeability. However, high SRT results in efficient settling of sludge and subsequently higher membrane permeability (Mannina et al., 2018). Overall, high values of both HRT and SRT favor higher permeability.

\subsection{Process optimization}

The optimal condition of three process variables of disk rotational speed, HRT, and SRT for maximum steady-state permeability was examined based on the desirability function. Parameter optimization was performed to determine the 
highest particular point, which amplifies the significant function i.e. steady-state permeability.

As shown in Fig. 4, the optimal conditions for maximum permeability ( $144.6 \mathrm{~L} / \mathrm{m}^{2} \mathrm{~h}$ bar) were found at a disk rotational speed of 36.1 rpm, HRT of 18 h, and SRT of 14.9 d, as shown in Fig. 4 and Table 7. The excellent agreement between predicted and experimental results confirms model validation to simulate the steady-state permeability.

Table 7

Optimized operational parameters values at maximum steady-state membrane permeability.

\begin{tabular}{|llllll|}
\hline \multicolumn{5}{|c|}{$\begin{array}{c}\text { Steady-state permeability } \\
\text { (L/m } \mathbf{m}^{2} \mathrm{~h} \text { bar) }\end{array}$} \\
\hline Variables & Optimum values & Predictive & Experimental & Error (\%) & Standard deviation \\
\hline Disk rotational speed & $36.1 \mathrm{rpm}$ & 144.6 & 144.5 & 0.44 & 1.18 \\
\hline HRT & $18.0 \mathrm{~h}$ & & & & \\
SRT & $14.9 \mathrm{~d}$ & & & & \\
\hline
\end{tabular}

To confirm the achieved results both from the experiments and model, two more experiments were performed using the optimum parametric values. Table 8 shows the experimental and model predictive values for the optimum condition. The steady-state permeability response of both the experimental and model values is in close agreement.

Table 8

Steady-state membrane permeability values for the model and experiment.

\begin{tabular}{|lllll|}
\hline \multicolumn{5}{|c|}{$\begin{array}{l}\text { Steady-state permeability } \\
\left(\mathrm{L} / \mathrm{m}^{2} \mathrm{~h} \text { bar }\right)\end{array}$} \\
\hline Run & Predictive & Experimental & $\begin{array}{l}\text { Error } \\
(\%)\end{array}$ & Standard deviation \\
\hline 1 & 143.5 & 143.00 & 0.35 & 0.26 \\
\hline 2 & 137.3 & 137 & 0.18 & 0.13 \\
\hline
\end{tabular}

\section{Conclusions}

This research applies RSM to optimize the biological and filtration performance of an RBC coupled with external membrane filtration. The RBC-ME bioreactor was a successful biological treatment process to achieve a high biological removal efficiency. The RBC exhibits $87.6 \pm 2.7 \%$ of COD, $45.2 \pm 2.6 \% \mathrm{TN}, 98.5 \pm 0.07 \%$ ammonia, and $97.8 \pm 0.2 \%$ turbidity removal efficiencies. The RSM results demonstrated the effects of the operating parameters as well as their interactive effects on permeability as the response. At higher disk rotational speeds (>35 rpm), the permeability decreased due to the higher shear rate and shredding of biofilm flocs. At higher HRT and SRT, higher permeability was obtained. By applying $\mathrm{RSM}$, the optimum region for the bioreactor operating conditions was located. The optimum conditions obtained were 144.6 L/m² $\mathrm{h}$ bar permeability at disk rotational speed $36.1 \mathrm{rpm}, 18 \mathrm{~h} \mathrm{HRT}$, and $14.9 \mathrm{~d}$ SRT. The results demonstrated good agreement amongst experimental and model predictions. It is evident from the current study that RSM is an efficient statistical optimization approach that can help to distinguish between the most important operational parameters at the 
cost of minimum time and effort. The development of the membrane integrated RBC system can significantly enhance the effluent quality to satisfy the stringent regulations and can serve as a promising alternative for decentralized application for the development of a sustainable environment.

\section{Declarations}

\section{Data Availability}

The datasets generated during and/or analysed during the current study are available from the corresponding author on reasonable request.

\section{Conflicts of Interests}

The authors have no conflicts of interest to declare that are relevant to the content of this article.

\section{Funding}

This work was funded by the Yayasan Universiti Teknologi PETRONAS (YUTP) with grant code YUTP-015LC0-210.

\section{Authors' contribution}

All authors contributed to the study conception and design. Material preparation, Conceptualization, Methodology, Investigation, Data curation, Formal analysis, Validation, Writing - original draft: Sharjeel Waqas; Funding acquisition, Supervision, Review \& editing: Noorfidza Yub Harun; Conceptualization, Project administration, Resources, Supervision, Writing - review \& editing: Muhammad Roil Bilad; Investigation, Data curation, Formal analysis: Taufik Samsuri; Supervision, Writing - review \& editing: Nik Abdul Hadi Nordin.

\section{Acknowledgements}

The authors would like to thank the Universiti Teknologi PETRONAS for providing the research facilities.

\section{References}

1. Abdulgader M, Yu QJ, Zinatizadeh AA, Williams P, Rahimi Z (2020) Application of response surface methodology (RSM) for process analysis and optimization of milk processing wastewater treatment using multistage flexible fiber biofilm reactor. Journal of Environmental Chemical Engineering 8(3):103797

2. APHA (1997) Standard methods for the examination of water and wastewater. American Public Health Association, Washington, D.C, USA

3. Ashraf A, Ramamurthy R, Rene ER (2021) Wastewater treatment and resource recovery technologies in the brewery industry: Current trends and emerging practices. Sustain Energy Technol Assess 47:101432

4. Askari N, Farhadian M, Razmjou A (2018) Simultaneous effects of pH, concentration, pressure on dye removal by a polyamide nanofilter membrane; optimization through response surface methodology. Environmental nanotechnology monitoring management 10:223-230

5. Baneshi MM, Ghaedi AM, Vafaei A, Emadzadeh D, Lau WJ, Marioryad H et al (2020) A high-flux P84 polyimide mixed matrix membranes incorporated with cadmium-based metal organic frameworks for enhanced simultaneous dyes removal: response surface methodology. Environmental research 183:109278

6. Belgada A, Charik FZ, Achiou B, Kambuyi TN, Younssi SA, Beniazza R et al (2020) Optimization of phosphate/kaolinite microfiltration membrane using Box-Behnken design for treatment of industrial wastewater. Journal of Environmental Chemical Engineering, 104972

Page $12 / 18$ 
7. Berkessa YW, Yan B, Li T, Tan M, She Z, Jegatheesan V et al (2018) Novel anaerobic membrane bioreactor (AnMBR) design for wastewater treatment at long HRT and high solid concentration. Bioresour Technol 250:281-289

8. Bezirgiannidis A, Marinakis N, Ntougias S, Melidis P (2018) Membrane bioreactor performance during processing of a low carbon to nitrogen ratio municipal wastewater. Environmental Processes 5(1):87-100

9. Bilad MR, Nawi NIM, Subramaniam DD, Shamsuddin N, Khan AL, Jaafar J et al (2020) Low-pressure submerged membrane filtration for potential reuse of detergent and water from laundry wastewater. Journal of Water Process Engineering 36:101264

10. Deng L, Guo W, Ngo HH, Du B, Wei Q, Tran NH et al (2016) Effects of hydraulic retention time and bioflocculant addition on membrane fouling in a sponge-submerged membrane bioreactor. Bioresour Technol 210:11-17

11. Fito J, Tefera N, Van Hulle SW (2019) An integrated treatment technology for blended wastewater of the sugar industry and ethanol distillery. Environmental Processes 6(2):475-491

12. Gkotsis P, Peleka E, Zamboulis D, Mitrakas M, Tolkou A, Zouboulis A (2017) Wastewater treatment in membrane bioreactors: The use of polyelectrolytes to control membrane fouling. Environmental Processes 4(1):9-21

13. Huang Z, Ong SL, Ng HY (2011) Submerged anaerobic membrane bioreactor for low-strength wastewater treatment: effect of HRT and SRT on treatment performance and membrane fouling. Water Res 45(2):705-713

14. Jang Y, Kim H-S, Ham S-Y, Park J-H, Park H-D (2021) Investigation of critical sludge characteristics for membrane fouling in a submerged membrane bioreactor: Role of soluble microbial products and extracted extracellular polymeric substances. Chemosphere, 129879

15. Liu R, Lin Y, Xu G, Li Y, Premalatha R, Chandran K (2021) Optimized hybridized mathematical model for wastewater treatment and energy generation using microbial fuel cells. Sustain Energy Technol Assess 47:101348

16. Luo J, Ding L, Wan Y, Jaffrin MY (2012) Flux decline control in nanofiltration of detergent wastewater by a shearenhanced filtration system. Chem Eng J 181:397-406

17. Malika M, Sonawane SS (2021) Statistical modelling for the Ultrasonic photodegradation of Rhodamine B dye using aqueous based Bi-metal doped TiO2 supported montmorillonite hybrid nanofluid via RSM. Sustain Energy Technol Assess 44:100980

18. Mannina G, Capodici M, Cosenza A, Di Trapani D, Ekama GA (2018) The effect of the solids and hydraulic retention time on moving bed membrane bioreactor performance. J Clean Prod 170:1305-1315

19. Nuansawan N, Boonnorat J, Chiemchaisri W, Chiemchaisri C (2016) Effect of hydraulic retention time and sludge recirculation on greenhouse gas emission and related microbial communities in two-stage membrane bioreactor treating solid waste leachate. Bioresour Technol 210:35-42

20. Preisner M (2020) Surface water pollution by untreated municipal wastewater discharge due to a sewer failure. Environmental Processes 7(3):767-780

21. Sheth Y, Dharaskar S, Khalid M, Sonawane S (2021) An environment friendly approach for heavy metal removal from industrial wastewater using chitosan based biosorbent: A review. Sustain Energy Technol Assess 43:100951

22. Šíma J, Pocedič J, Hasal P (2016) Decolorization of reactive orange 16 in rotating drum biological contactor. Journal of Environmental Chemical Engineering 4(4):4540-4548

23. Su C, Deng Q, Lu Y, Qin R, Chen S, Wei J et al (2019) Effects of hydraulic retention time on the performance and microbial community of an anaerobic baffled reactor-bioelectricity Fenton coupling reactor for treatment of traditional Chinese medicine wastewater. Bioresour Technol 288:121508

24. Vasiliadou I, Pariente M, Martinez F, Melero J, Molina R (2016) Modeling the integrated heterogeneous catalytic fixedbed reactor and rotating biological contactor system for the treatment of poorly biodegradable industrial agrochemical wastewater. Journal of environmental chemical engineering 4(2):2313-2321 
25. Waqas S, Bilad MR (2019) A review on rotating biological contactors. Indonesian Journal of Science Technology 4(2):241-256

26. Waqas S, Bilad MR, Aqsha A, Harun NY, Ayoub M, Wirzal MDH et al (2020a) Effect of membrane properties in a membrane rotating biological contactor for wastewater treatment. Journal of Environmental Chemical Engineering, 104869

27. Waqas S, Bilad MR, Huda N, Harun NY, Nordin Md, Shamsuddin NAH, N., et al (2021a) Membrane Filtration as PostTreatment of Rotating Biological Contactor for Wastewater Treatment. Sustainability 13(13):7287

28. Waqas S, Bilad MR, Man Z, Wibisono Y, Jaafar J, Mahlia TMI et al (2020b) Recent progress in integrated fixed-film activated sludge process for wastewater treatment: A review. J Environ Manage 268:110718. doi:10.1016/j.jenvman.2020.110718

29. Waqas S, Bilad MR, Man ZB (1793) (2021b) 'Effect of organic and nitrogen loading rate in a rotating biological contactor for wastewater treatment' Journal of Physics: Conference Series. IOP Publishing, p. 0120631

30. Waqas S, Bilad MR, Man ZB (2021c) Performance and Energy Consumption Evaluation of Rotating Biological Contactor for Domestic Wastewater Treatment. Indonesian Journal of Science Technology 6(1):101-112

31. Waqas S, Bilad MR, Man ZB, Klaysom C, Jaafar J, Khan AL (2020c) An integrated rotating biological contactor and membrane separation process for domestic wastewater treatment. Alexandria Engineering Journal 59(6):4257-4265

32. Waqas S, Bilad MR, Man ZB, Suleman H, Nordin NAH, Jaafar J et al (2021d) An energy-efficient membrane rotating biological contactor for wastewater treatment. J Clean Prod 282:124544

33. Zhang W, Grimi N, Jaffrin MY, Ding L (2015) Leaf protein concentration of alfalfa juice by membrane technology. J Membr Sci 489:183-193

34. Zulfiqar M, Chowdhury S, Omar AA, Siyal AA, Sufian S (2020a) Response surface methodology and artificial neural network for remediation of acid orange 7 using TiO 2-P25: optimization and modeling approach. Environ Sci Pollut Res 27(27):34018-34036

35. Zulfiqar M, Samsudin MFR, Sufian S (2019) Modelling and optimization of photocatalytic degradation of phenol via TiO2 nanoparticles: An insight into response surface methodology and artificial neural network. J Photochem Photobiol A 384:112039

36. Zulfiqar M, Sufian S, Mansor N, Rabat NE (2020b) Synthesis and characterization of TiO2-based nanostructures via fluorine-free solvothermal method for enhancing visible light photocatalytic activity: Experimental and theoretical approach. J Photochem Photobiol A 404:112834

\section{Figures}




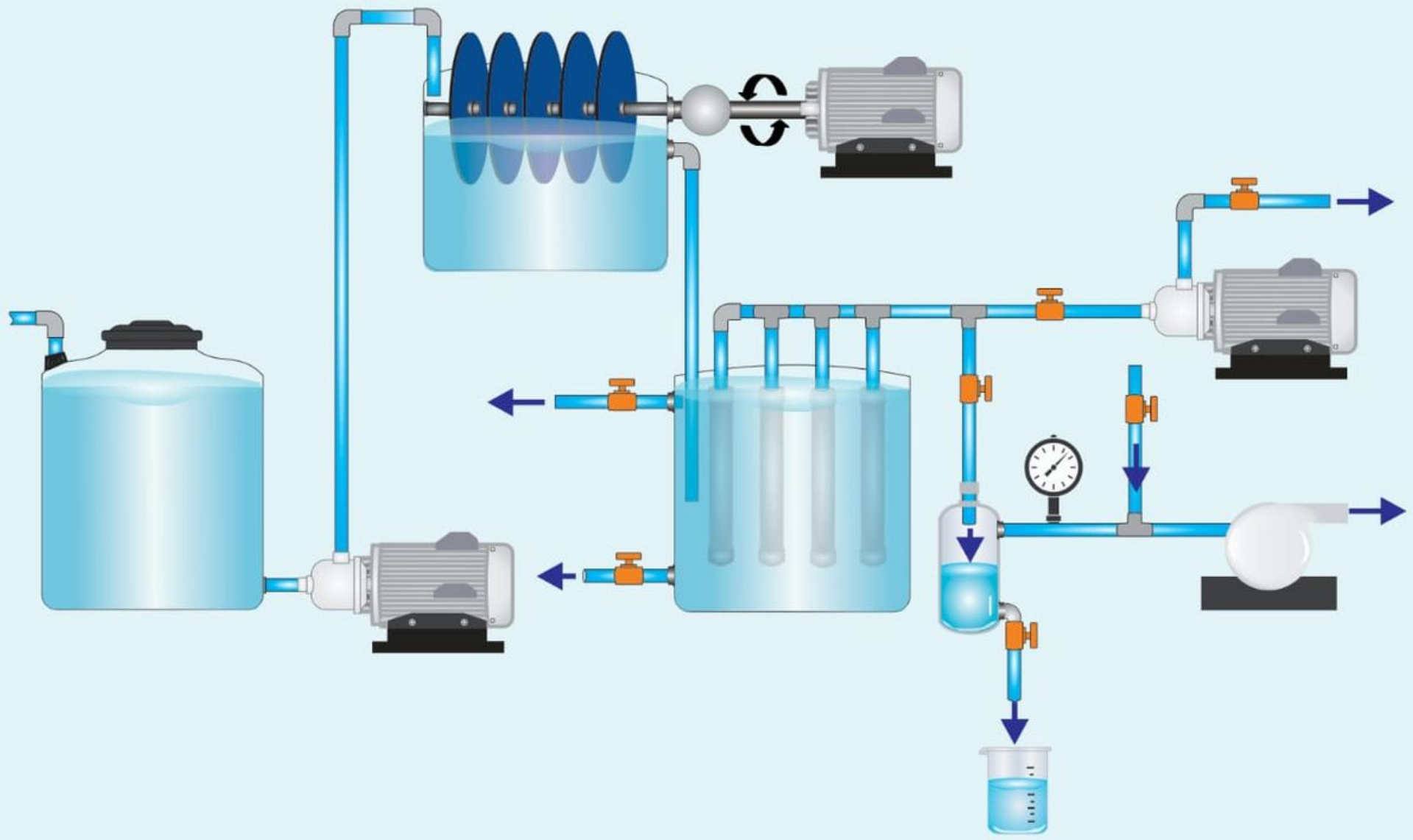

Figure 1

Schematic diagram of RBC-ME configuration. 


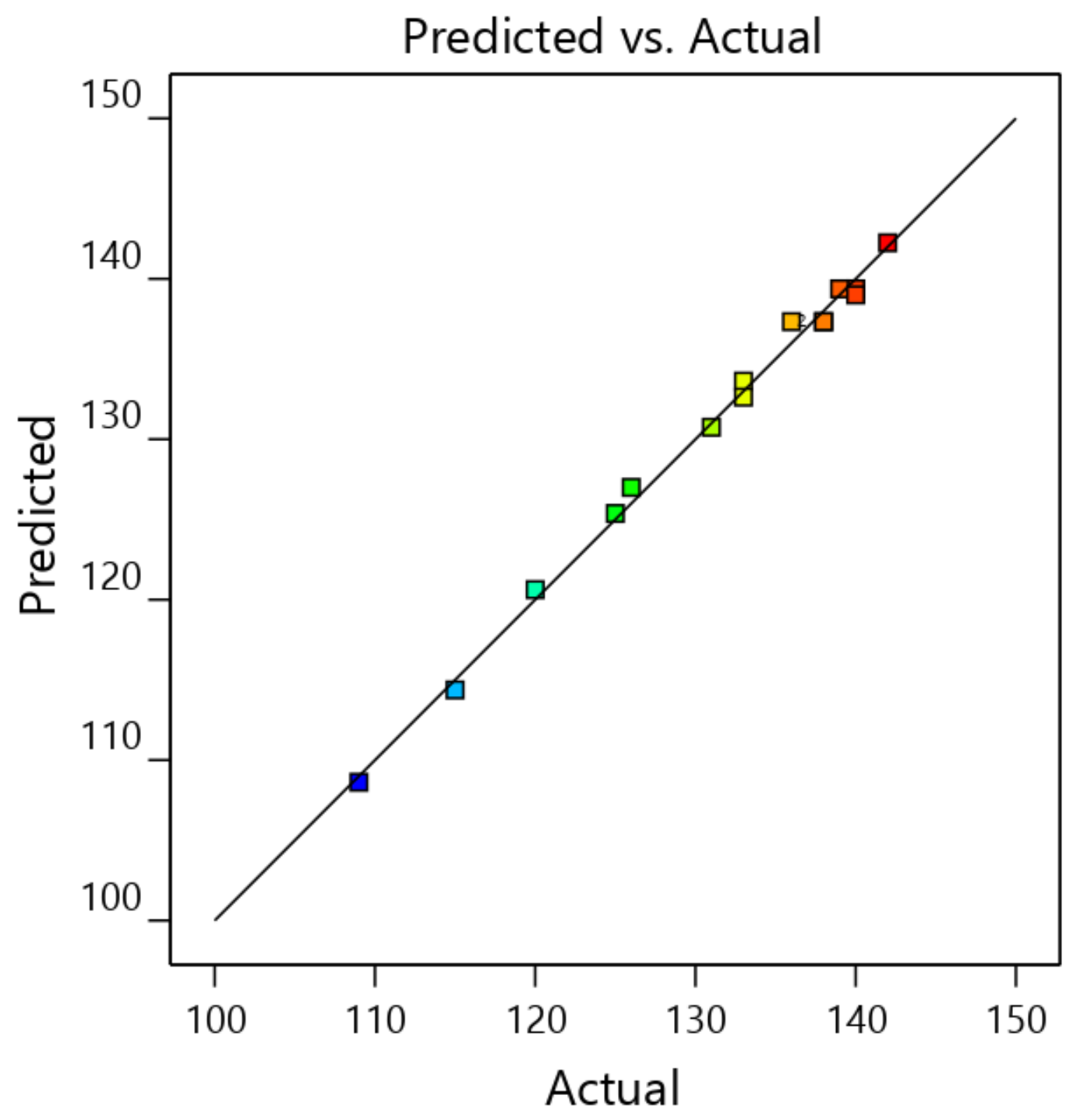

Figure 2

Design-expert plot; predicted vs. actual values plot for steady-state permeability. 

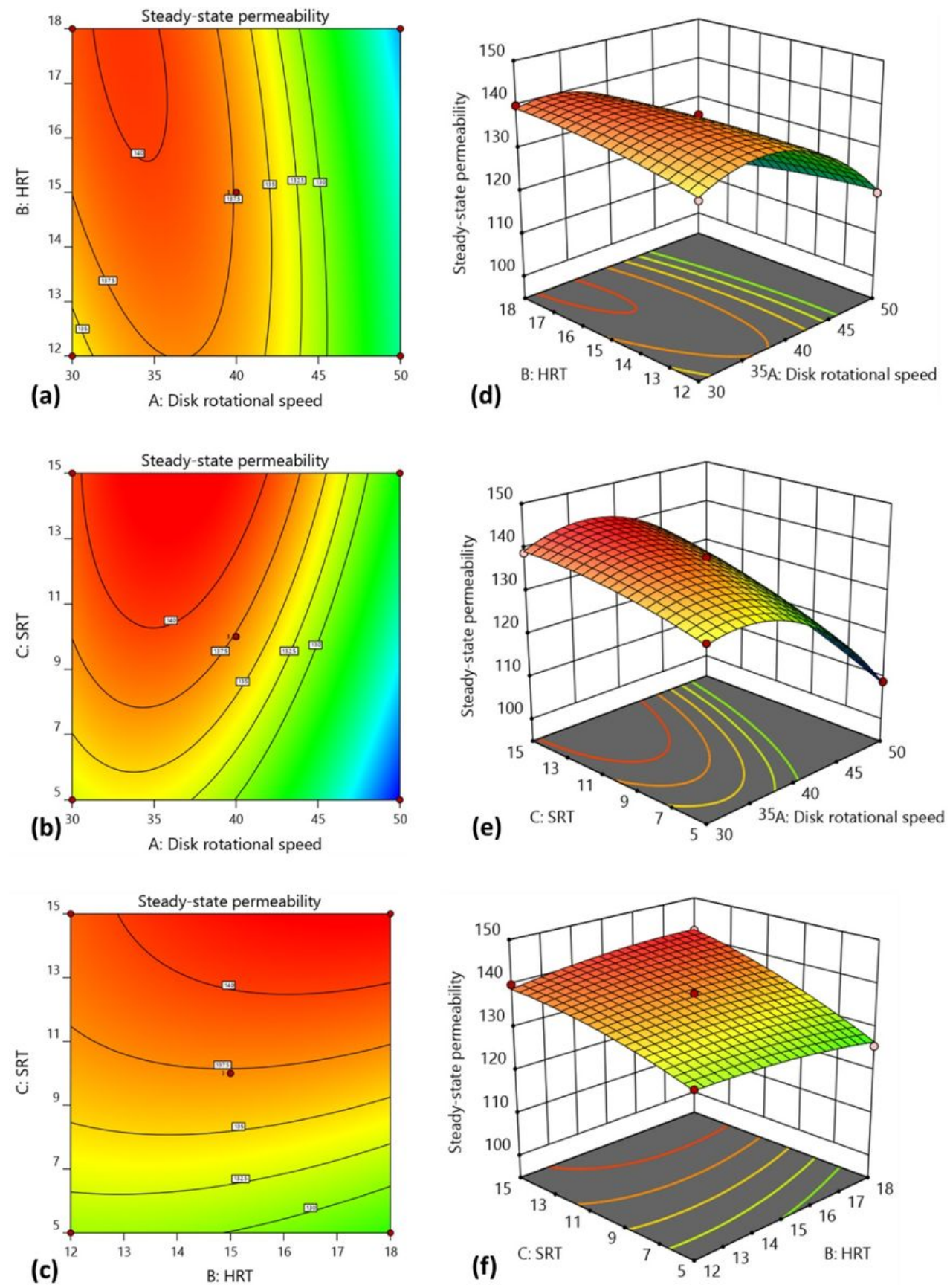

Figure 3

Effect of 2-D counter of (a) disk rotational speed and HRT (b) disk rotational speed and SRT (c) HRT and SRT and 3-D response surface plots of (d) disk rotational speed and HRT (e) disk rotational speed and SRT and (f) HRT and SRT. 


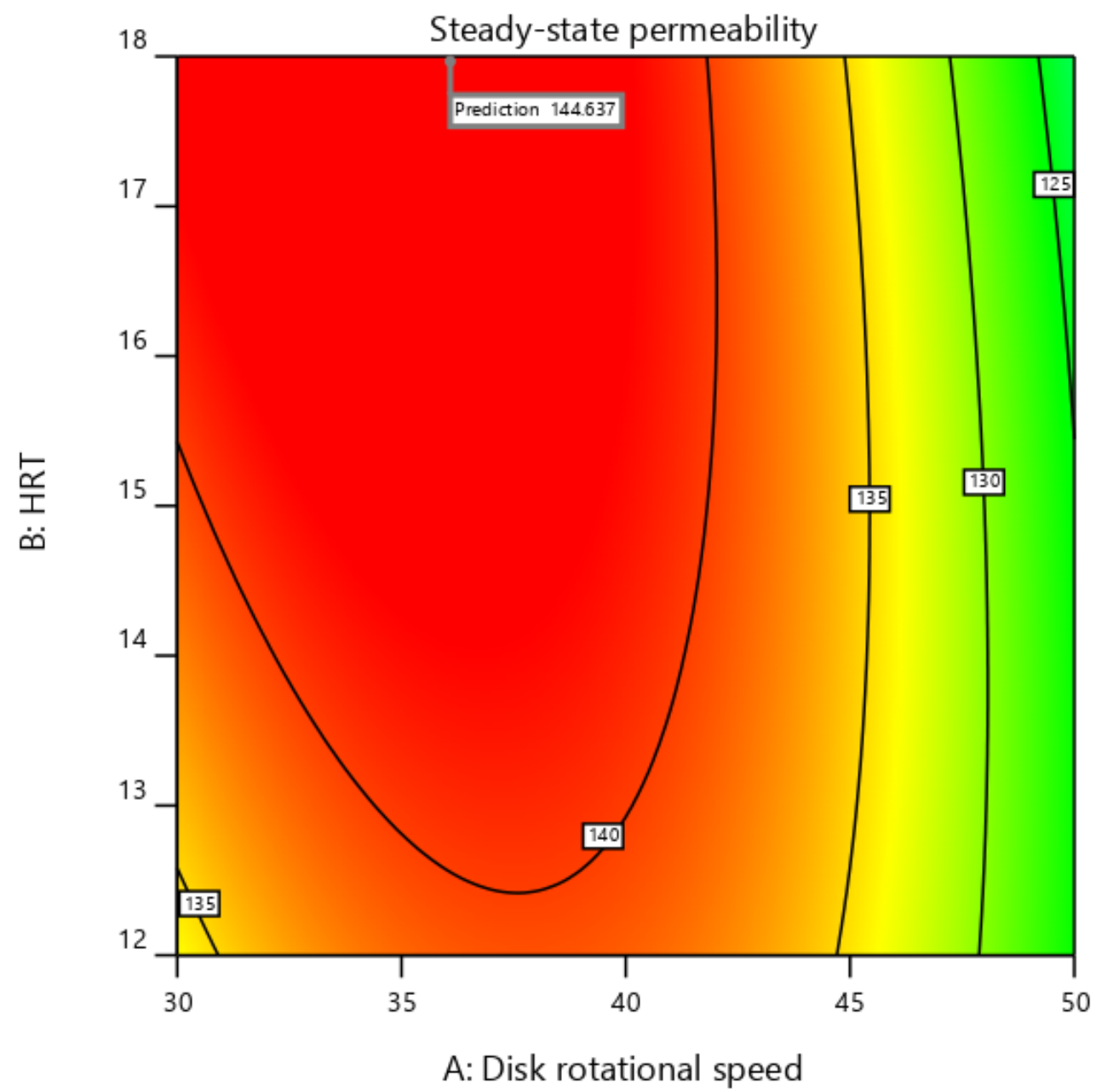

Figure 4

Process optimization values of the operational parameters at maximum steady-state membrane permeability. 